\title{
Deformation analysis of the seismic and post-seismic Cheliff (Algeria) geodetic network using 2D elastic Finite Element Method (FEM)
}

\author{
Bachir GOURINE $^{(1)}$ and Farida BACHIR BELMEHDI ${ }^{(2)}$
}

(1) Centre of Space Techniques (CTS), Department of Space Geodesy. BP n 13, 1 av. de la Palestine, Arzew - Algeria, Tel. +213 41793042, Fax.+213 41 792176, Email: bachirgourine@yahoo.com ; bgourine@cts.asal.dz

(2) University of Oran 2, Faculty of Earth Sciences and Universe, Department of Geography, Oran - Algeria. Email : bachirbelmehdi.farida@yahoo.com

\begin{abstract}
:
The region of Cheliff, located at the North West of Algeria, is one of an exceptional interest for crustal motion study which is due to seismic activity. Usually, in the deformation analysis of geodetic networks, there are two conventional methods for estimating the movements of an area of study: displacement vectors and strain tensors. However, the evaluation and representation of the deformation depend on the priori reference system and on the configuration of chosen elements that constitute the entire network. These constraints make difficult the interpretation of the results. Through this present paper, a solution based on the finite element method (FEM) is proposed to refine the estimation and the representation of the deformation of geodetic networks. In this context, a study of the deformation is carried out to analyze the horizontal motion of the Cheliff geodetic network due to the famous earthquake of October 10, $1980(\mathrm{Ms}$ $=7.3$ ), based on two-dimensional elastic finite element model. This network was observed by classical triangulation in 1976 (by INCT) and in 1981 (by CRAAG). The different results are illustrated in terms of displacement vectors, strain and stress tensors where the estimated deformation is interpreted according to previous geophysical studies. They revealed a compressive phenomenon of Cheliff area, in the NNW-SSE orientation, due to the convergence of the African and Eurasian tectonic plates, and to a block rotation phenomenon, at the SE and NW parts of the fault, in a retrograde direction. The study was extended to the post-seismic geodetic network observed between June1990 and April 1992 by CRAAG. The network was established by distance measurements, with 12 monitoring points distributed along the reverse fault. The results obtained show a post seismic meaningful deformation, in the fault central segment, characterized by global NW-SE direction of strain tensors in agreement with ground data.
\end{abstract}

Key Words: Deformation, Displacement, Finite element method, Strain Tensor, Geodetic Network.

\section{Introduction}

Measuring the deformation of geodetic networks is an operation that, sometimes, takes a great economic or scientific importance. It is used in many cases, for example to monitor almost the big structures (dams, bridges, storage tanks, ...) [6], but also to follow certain natural phenomena capable of inducing significant natural hazards such as landslides, earthquakes, crustal movements, etc. Such measurements are important to knowing the mechanical functioning of the lithosphere, under variable constraints.

Generally, the methodology employed consists in establishing a precise and homogeneous geodetic network, covering the area of study. The network benchmarks are determined thanks to terrestrial and/or space positioning techniques (GNSS). The reiteration of the observations of the same network, after a certain period, permits to detect the movements appeared during this time, by coordinate's variation estimation.

There are two methods to evaluate these movements [13-15]: vector-displacements and strain tensors. Considered as gradient of the displacement field, the strain tensors represent a very efficient tool to perform the deformation computation and can be very helpful to analyse the behaviour of the studied area [10]. Unlike to the vector-displacements, they are independent of any reference frame which makes very delicate the interpretation of the movements. Nevertheless, the strain tensors computation depends on the configuration of the selected elementary figures formed from the geodetic points. This constraint makes difficult the interpretation of the results obtained [7].

To overcome this drawback, the finite element method (FEM) presents an appropriate solution for homogeneous and continuous representation of network deformation [1-7]. This method has become one of the most important and useful engineering tools for engineers and scientists. It is a numerical procedure, generally used for solving engineering problems (represented by partial differential equations with boundary 
conditions) with considering the physical and mechanical properties of the ground and the available external forces [2].

The objective of this paper is double. In one hand, it consists of the application of the FEM to evaluate the deformations of the geodetic network of Cheliff (North of Algeria) due the famous earthquake of October 10, $1980(M s=7.3)$, and in other hand, to study the post seismic activity of this region.

The data concern the seismic geodetic network of Cheliff observed by classical triangulation in 1976 and 1981, and post-seismic geodetic network measured by distance measurements in 1990 and 1992, see section (3). The analysis methodology adopted, based on FEM, is described in section (2). The different results obtained are presented and discussed in section (3).

\section{Finite Element Method}

The finite element method is a numerical procedure for solving engineering problems which are represented by partial differential equations (PDEs), with boundary conditions. It assumes discretization of the domain by a set of sub-domains called the finite elements. Throughout this paper, linear elastic behaviour is assumed. According to the fundamental equations of continuum mechanics, the equations of motion and compatibility equations of displacements of a volume $V$ of limit $S$ can be derived. Therefore, the general equations of the boundary value problem in solid mechanics are expressed as follows:

$$
\left\{\begin{array}{l}
\varepsilon=L \cdot U \\
L^{T} \sigma+P=0 \\
L_{l}^{T} \sigma=q \\
\sigma=f(\varepsilon)
\end{array}\right.
$$

where $\varepsilon$ denotes the strain deformation vector and $\sigma$ is the stress vector, $P$ is the vector of force volume, $q$ is the vector of force surface, $U$ is the displacement vector, $L$ and $L_{l}$ are differential operators. A linear elastic medium may be modelled directly by using the displacement of finite elements method. The equilibrium condition of displacement for approximation by finite element is given by [12]:

$$
[K] \cdot\{U\}=\{F\}
$$

where:

$[K]$ is the global stiffness matrix.

$\{U\}$ is the vector of displacements of the nodes for the whole structure, in a global coordinate system.

$[F]$ is the vector of loads on the structure.

Generally, we can summarize the finite element analysis method as follows, [8]:

- Step 1. Discretizing the domain - this step involves subdividing the domain into elements and nodes. For continuous systems like plates and shells this step is very important and the answers obtained are only approximate. In this case, the accuracy of the solution depends on the discretization used.

- Step 2. Computation of the element stiffness matrices - the element stiffness equations need to be computed for each element in the domain.

- Step 3. Assembling the global stiffness matrix.

- Step 4. Applying the boundary conditions - like supports and applied loads and displacements.

- Step 5. Solving the equations - this will be done by partitioning the global stiffness matrix and then solving the resulting equations using Gaussian elimination.

- Step 6. Post-processing - to obtain results as the reactions and element forces, strains and stresses.

The following figure illustrates the flow-chart of the FEM method adopted for the Chellif network analysis. 


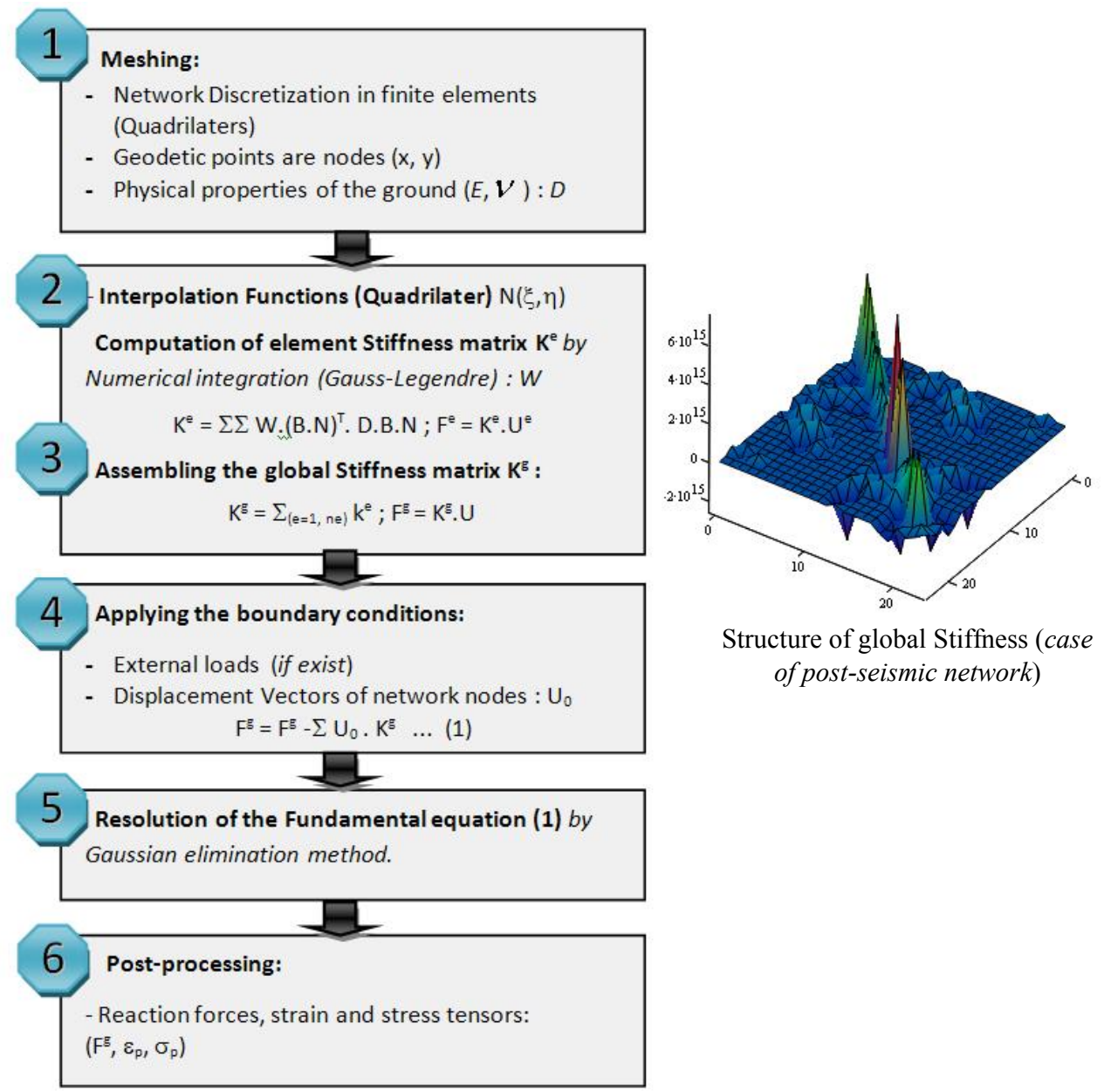

Fig.1: Flow-chart of the FEM applied to Cheliff network analysis [7]

\section{Results and discussion}

The Centre for Research in Astronomy, Astrophysics and Geophysics (CRAAG) has conducted geodetic observations to study the crustal movements related to the seismicity of the region of Cheliff and particularly the study of the fault caused by the earthquake of October 10, 1980. In June 1981, the first assessment of vertical and horizontal movements by geodetic methods was carried out by re-observing the local geodetic network which was already established by the National Institute of Cartography and Remote Sensing (INCT) in 1976. The observed triangulation network is constituted of 14 geodetic points distributed on both sides of the fault. Geographically, it is limited between $\left(1^{\circ} 19\right.$ 'and $1^{\circ} 39^{\prime}$ East) in longitude and $\left(36^{\circ} 02\right.$ 'and $36^{\circ}$ $23^{\prime}$ North) in latitude, figure (1). The number of points are designed by alphabetical letters (A, B, .., N). In 1976, the network had been observed only with angular measurements using first-order triangulation procedures and WILD T3 Theodolites. The accuracy was estimated at a few decimetres for relative position of the different points. A second observation campaign was conducted in 1981, using the same procedures and instruments. The Geodimeter AGA 14A was used to measure distances in the northern and southern parts, in order to provide a precise scaling of the network [14].

To assess the post-seismic effect on the region, another monitoring network was established inside the Cheliff geodetic network. Limited between ( $1^{\circ} 24^{\prime}$ and $1^{\circ} 36^{\prime}$ East) in longitude and ( $36^{\circ} 07^{\prime}$ and $36^{\circ} 15^{\prime}$ North) in latitude, this network was carried out to supervise the reverse fault and to assess the evolution of ground deformation surrounding this fault [14]. The network considered consists of 12 points including 03 reference points and 09 monitoring points. It was observed by trilateration during two observation campaigns, in June 1990 and April 1992 (works undertaken by the CRAAG). The number of points are designed by Arabic numbers $(101,102, . ., 112)$. The majority of measured triangle sides vary between $4.5 \mathrm{~km}$ and $7.3 \mathrm{~km}$ and the modal value is $6 \mathrm{~km}$. The distances between network points were measured with the distance meter (Di20) with accuracy of about $\pm 5 \mathrm{~mm}+10^{-6} \mathrm{D}(\mathrm{km})$. They are corrected from atmospheric effects and reduced according to the UTM projection associated to Clarke 1880A reference ellipsoid of Nord Sahara 1959 (NS59) datum. The estimated accuracy of the network point is about of few centimetres. 


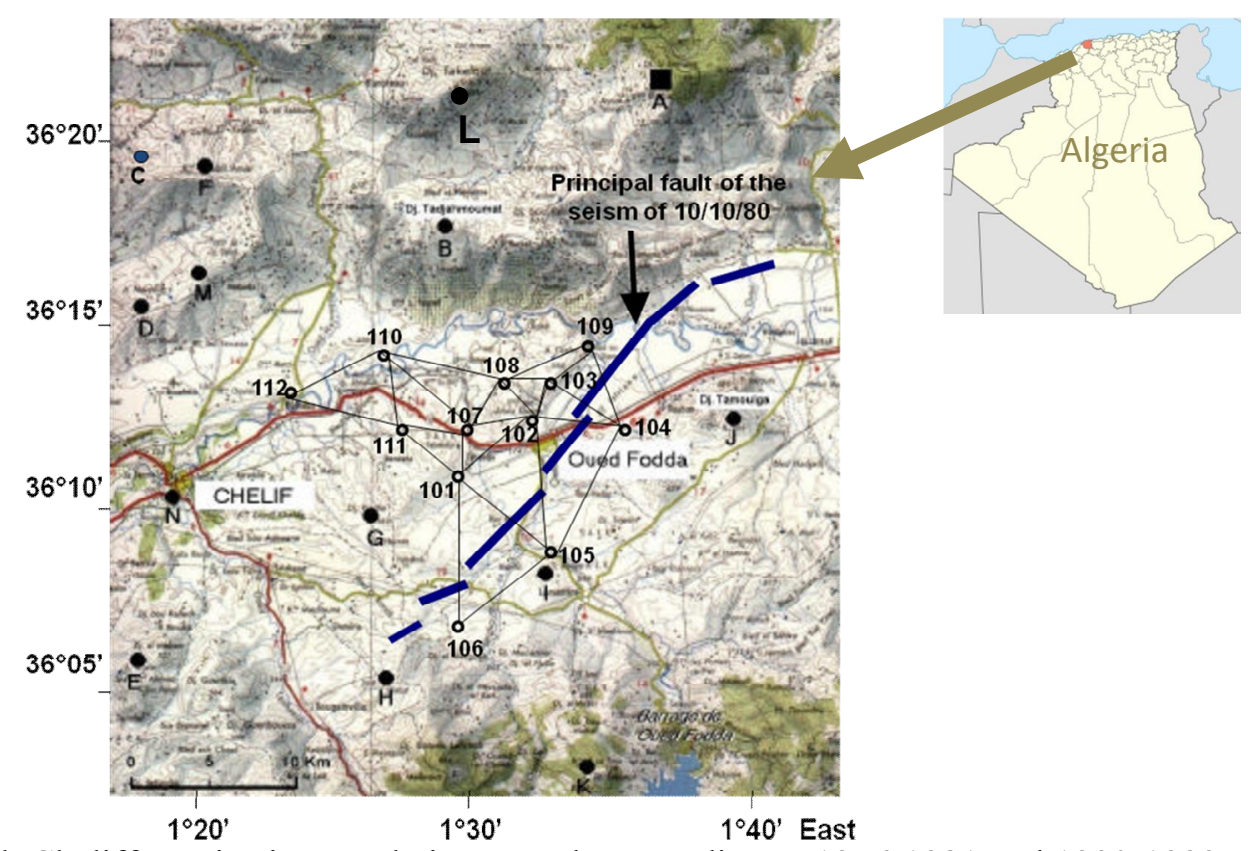

Fig. 2: Map of both Cheliff monitoring geodetic networks according to 1976-1981 and 1990-1992 periods.

In our case, the adopted values of the physical characteristics of the region are given by: $\left[\begin{array}{c}E \\ v \\ b\end{array}\right]=\left[\begin{array}{l}100 \times 10^{9} \\ 0.3 \\ 15000 \mathrm{~m}\end{array}\right]$

The values of Young's module E and Poisson's coefficient $v$ are simulated and taken from similar case of our area as cited in [4]. The ground thickness $b(\mathrm{~m})$ is taken from [14].

Figure (3) illustrates the deformation results related to the seismic monitoring network. The displacement vectors of the points $(\mathrm{H}, \mathrm{I}, \mathrm{J})$ and $(\mathrm{M}, \mathrm{B}, \mathrm{L})$ are directed in two opposite directions, NW and SE, respectively, according to the fault. The displacement vectors of the other points $(K, G, E, D, F, C)$ describe a block rotation in retrograde direction. In another hand, a shortening phenomenon of distances is observed between network nodes, particularly those located on both sides of the main fault, which can reach $-2 \mathrm{~m}$, this justifies the hypothesis of compressive motion and overlapping NO part over the SE one, given by geophysicists.

For the strain tensors, which are depicted according to the deformation principal components, the results show a predominance compression of about $150 \mathrm{ppm}$, especially on both sides of the main fault with maximum of $360 \mathrm{ppm}$, with perpendicular directions. This global trend of NW-SE shortening is similar to that deduced by tectonic observations (Philip et al., 1983) or focal mechanisms [3]. The presence of distensive faults on overlapping compartment, area where the movements are generally compressive, is due to an extrados extension and to gravitational effects [11]. There is also a change in direction of the deformation tensors from NW-SE to NE-SW, in the retrograde direction, from SW to NW of the fault, which confirms the presence of a block rotation phenomenon.

According to Ruegg et al. [14], we are in a case of inelastic finite dislocations (presence of fault and fracture). Therefore, the mean deformation tensor is only a compact and intrinsic representation of the deformation within the finite element considered. However, it would be wise to consider the dislocation modelling of Cheliff network, by FEM. For this purpose, recent studies about dislocation based FEM modelling have been conducted by [1-5].

The dilatation is represented by circles with proportional radii to deformation amplitudes. The red circles are dilatations and the blue ones are compressions. These later are observed over the entire of study area, particularly along the fault. Large compressions, of about $-180 \mathrm{ppm}$, are on the SW extremity of the fault which indicate the block rotation and overlapping of NW block on East one. However, some points have undergone dilatations of about $30 \mathrm{ppm}$, such as (B, C, E and I). The shear expresses the change of configuration of the element. The results indicate high deformation of about $250 \mathrm{ppm}$ around the fault, except for the NW region where the shear is weak and at level of $20 \mathrm{ppm}$. 

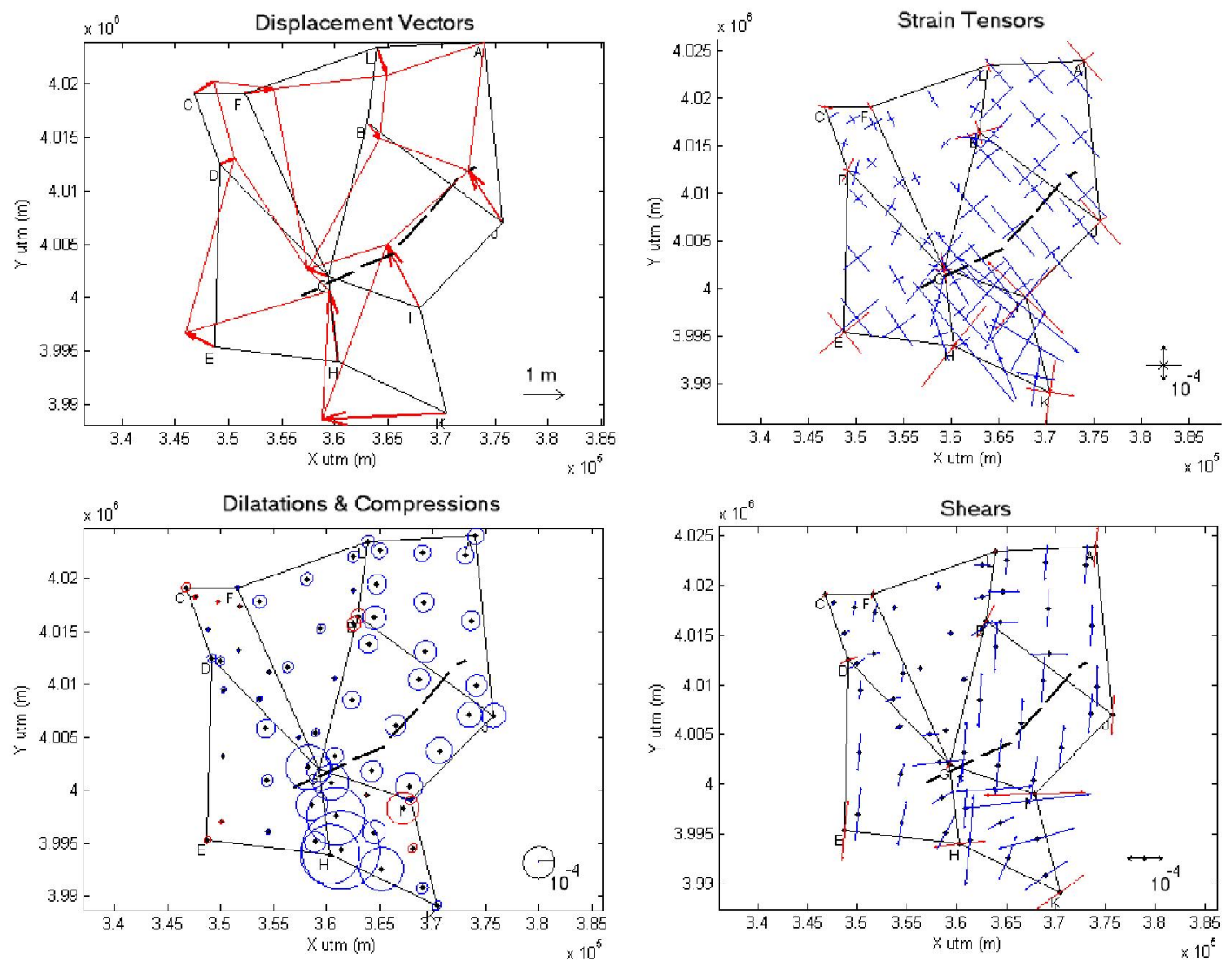

Fig. 3: Displacement vectors and deformation field of Cheliff seismic geodetic network.

Figure (4) illustrates the deformation results related to the post-seismic monitoring network. The average of displacements vectors are of about $30 \mathrm{~cm}$. The maximum value is reached at the point 110 with $68 \mathrm{~cm}$. The orientation of these vectors describes a rotation in NE-E direction.
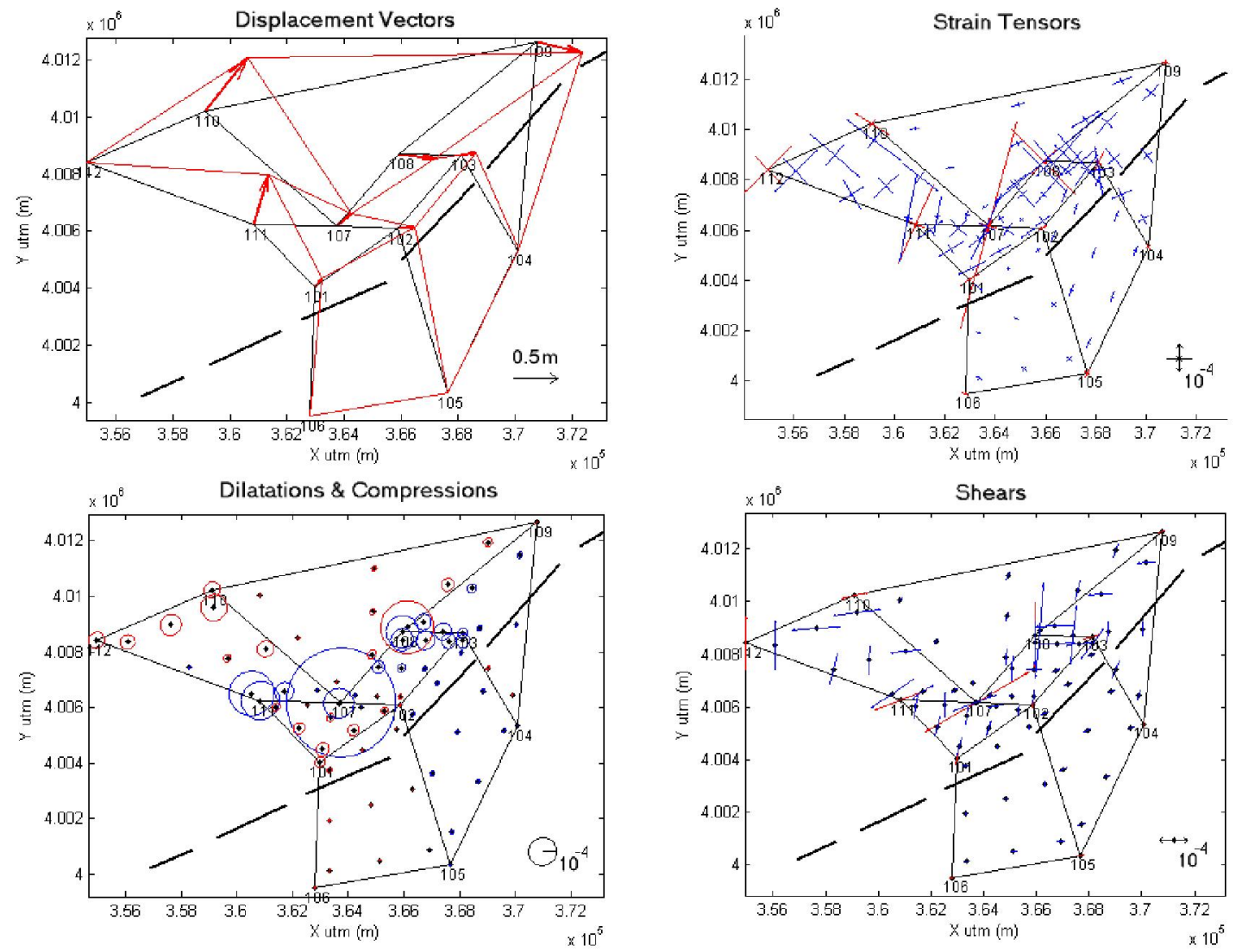

Fig. 4: Displacement vectors and deformation field of Cheliff post-seismic geodetic network. 
One can distinguish two regions of deformation. The first concerns the compression which is surrounding the fault of range of 10-100 ppm with maximum of $400 \mathrm{ppm}$ at the point 107 . However, the second one concerns the dilatation, mainly is in the North part of about 10-60 ppm. Total shears of these regions are represented by vectors proportional to their values which are enough intense, particularly at the north side of the fault with NW-SE direction. Such results confirm the hypothesis proposed by [9] which consists of the existence of two sliding dextral faults in the NW-SE direction, explaining the shift between the central segment and SE segment of the fault.

\section{Conclusion}

In this paper, the 2D finite element method (FEM) was successfully applied for the estimation and representation of Cheliff monitoring networks deformation. It allows easy reading and interpretation of horizontal movements. Our different results are expressed in terms of displacement vectors and strain tensors, they highlighted the following geophysical phenomena:

- A compressive phenomenon, in the NNW-SSE direction, due to the convergence of the African and Eurasian tectonic plates that caused the thrust fault of the famous earthquake of 10 October 1980.

- A block rotation phenomenon, at the SE and NW parts of the fault, in a retrograde direction.

- A significant post-seismic deformation at level of the central segment of the fault which can be considered as a pre-seismic factor to not neglect.

As perspectives, it is interesting to perform statistical analysis of deformation errors by Monte Carlo method and to adopt dislocation model with FEM deformation representation.

\section{References}

[1] M. Abolghasem and E. W. Grafarend. Finite element analysis of quasi-static earthquake displacement fields observed by GPS. Journal of Geodesy,Vol. 77, No. 9, 529-536,2003.

[2] G. Dhatt et G. Touzot, Une présentation de la méthode des éléments finis. Presses de l'Université Laval Québec, Maloine S.A. Ed. Paris, 543p, 1981.

[3] A. Cisternas, Dorel J., Gaulon R. Models of the complex source of the EL-ASNAM earthquake. Bull. Seism. Soc. Am., Vol. 72, Nº, pp. 2245-2266, 1982.

[4] C. Dingbo, Caijun X. and Jingnan L. Analyses of the crustal deformations in the Tibetan Plateau with three dimension elastic finite element method. Sciences Reports 1996 of the school of Geoscience and Surveying Engineering, WTUSM (China), Ed. 1997, pp 01-09.

[5] D. Güney, M. Acar, M. T. Özlüdemir, and R. N. Celik. Investigation of post-earthquake displacements in viaducts using Geodetic and Finite Element Methods. Nat. Hazards Earth Syst. Sci., 10, 2579-2587, 2010.

[6] B. Gourine, H. Mahi, A. Khoudiri and Y. Laksari, 2012. The GRNN and the RBF neural networks for 2D displacement field modelling. Case study: GPS auscultation network of LNG reservoir (G14/Z industrial complex - Arzew, Algeria). Proceedings of FIG Working Week, Rome, Italy, 6-10 May 2012.

[7] B. Gourine, B. Ghezali, 2013: Analyse préliminaire des déformations du réseau géodésique de Cheliff (Algérie), entre 1976 et 1981, par la méthode des éléments finis 2D. Revue "Nature \& Technologie", A-Sciences fondamentales et Engineering, $n^{\circ} 08 / J a n v i e r ~ 2013$, pp 50-58, Issn: 1112-9778.

[8] H. Oudin, Méthode des éléments finis, Notes de Cours v.1, Ecole Centrale de Nantes - France, Novembre 2008.

[9] M. Ouyed, Meghraoui M., Cisternas A., Deschamps A., Dorel J., Frechet, Gaulon R., Hatzfeld D., Philip H. Seismotectonics of the EL-ASNAM earthquake. Nature, Vol. 292, №5818, pp.26-31, 1981.

[10] J. Pagarette, Kasser M. and Ruegg J. C. Évaluation et représentation des erreurs sur les déformations d'un réseau géodésique : utilisation de la méthode de Monté Carlo. Bull. Géod. 64, pp 63-72, 1990.

[11] H. Philip, Meghraoui M. Structural analysis and interpretation of the surface deformations of the EL-ASNAM earthquake of 10 October 1980. Tectonics, Vol. 2, Nº1, pp. 17-49, 1983.

[12] R. M. Richardson. Finite element method of stress in the Nazca plate: driving forces and plate boundary earthquake. Tectono-physics, 50, pp 223-248, 1978.

[13] Prescott, W. H., Savage, J. C., and kinoshita, W. T. (1979). Strain accumulation rates in the western United States between 1970 and 1978. J. Geophys. Res., 84, 5423-5435.

[14] J.C. Ruegg, Kasser M., Tarantola A., Lepine J.C. and Chouikrat B. Deformation associated with the EL-ASNAM earthquake of 10 October 1980: Geodetic determination of vertical and horizontal movements. Bull. of seismological society of America, vol. 72, n6, pp 2227-2244, December 1982.

[15] Welsch, W. (1983). Finite element analysis of strain patterns from geodetic observations across a plate margin. Tectonophysics. 97, pp. 57-71. 